attention to some places in Sweden where this denuding power also could be traced. Prof. Torell also mentioned the marine fauna at Gothenburg, and Mr. Börtzell made some remarks on the deep-boring at Gothenburg.

Geologiska Föreningens Förhandingar. Stockholm. No. 32 . Contexts.

1. Meeting. April 2, 1876.

2. C. W. Blomstrand. Bidrag till kännedomen om Yängbansgrufvans mineralier. (Contribution to the Knowledge of the Minerals of the Längban-mine in Sweden.)

3. A. M. Jenrström. Om Finlands postglaciala skalgrusbäddan. (On the Postglacial Shell-beds in Finland.)

4. E. Erdmann. Profil genom en rullstensäs. (Section of a Swedish " Ås"Kames, Eskers-consisting of stratified sand and gravel with boulders.)

5. Swedish, Norwegian, Finlandic, and Danish geological literature published during 1875 .

\title{
COREESPONDEINCF.
}

APPARENT AND TRUE DIP.

SIR,-Mr. Penning's very simple construction for direction of dip, given in the May Number of this MAGAzINE, is only approximate, and in extreme cases might be rather widely wrong. In the case he has taken for his figure the error will be about $3^{\circ}$; in the case of dips of $30^{\circ}$ and $60^{\circ}$ at right angles to each other, his construction would be $8^{\circ}$ wrong.

The accurate rule would be as follows:-

Draw two lines from a point in directions of the two observed dips. Set off along each line lengths proportional to the tangent of the other dip (or to the cotangent of its own). Join the ends of these lengths: the joining line will be the direction of the strike, the perpendicular to it from the angle will be the direction of the dip.

Moreover, if cotangents have been used, the length of this perpendicular is proportional to the cotangent of the true dip, whose magnitude as well as direction will thus be determined by one construction.

Mr. Penning's construction would give the magnitude of the dip by the formula : Length of perpendicular : length of a side $::$ dip in direction of other side : true dip. And as accurate values of dips are usually needless, this would probably give sufficiently correct results.

Mr. Penning's rule, as any one acquainted with Trigonometry may see, is equivalent to assuming that angles are proportional to their tangents.

E. HiLL.

Cambridge, May 23rd, 1876.

\section{SOUTH AUSTRALIAN POST-TERTIARY FORAMINIFERA AND} OSTRACODA.

SIR,-A notice of the occurrence of the following species of Foraminifera and Ostracoda in the Post-Tertiary beds of South Australia may be of interest to some of your readers. A small collection of Mollusca was presented to the Museum of Practical Geology, London, many years ago, by Mr. H. Challoner, of the Burra-Burra Mines, South Australia. From the matrix contained in and surrounding these the minute fossils were washed by Mr. J. Bennie and myself. 